\title{
Polynesian people used binary numbers 600 years ago
}

\section{Base-2 system helped to simplify calculations centuries before Europeans rediscovered it.}

\section{Philip Ball}

16 December 2013

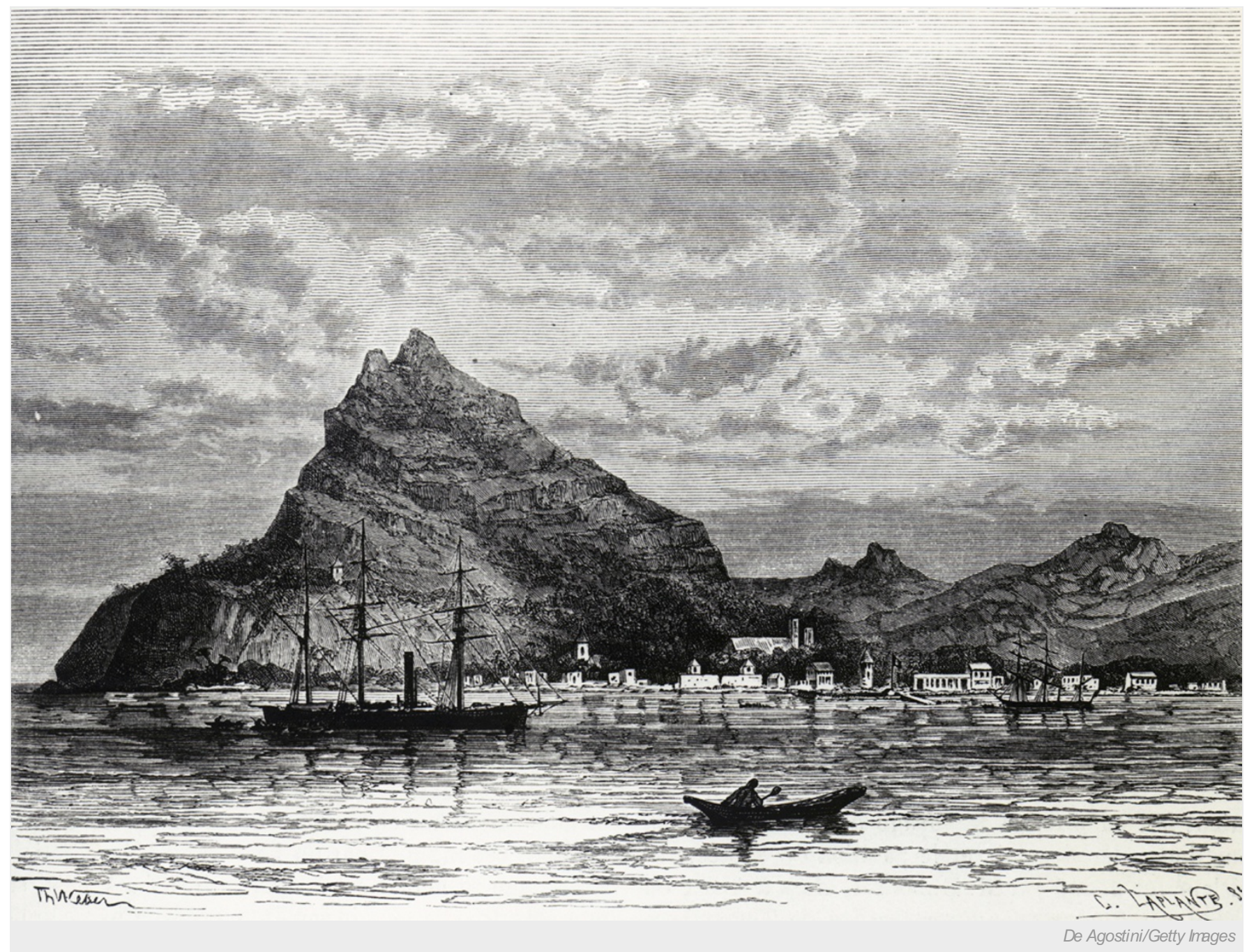

Before France colonized Mangareva Island and began to assimilate it, the natives' language contained words that enabled simple binary calculations.

Binary arithmetic, the basis of all virtually digital computation today, is usually said to have been invented at the start of the eighteenth century by the German mathematician Gottfried Leibniz. But a study now shows that a kind of binary system was already in use 300 years earlier among the people of the tiny Pacific island of Mangareva in French Polynesia.

The discovery, made by analysing historical records of the now almost wholly assimilated Mangarevan culture and language and reported in Proceedings of the National Academy of Sciences ${ }^{1}$, suggests that some of the advantages of the binary system adduced by Leibniz might create a cognitive motivation for this system to arise spontaneously, even in a society without advanced science and technology.

Pure binary arithmetic works in base 2 rather than the conventional base 10, which many cultures have adopted possibly as a consequence of counting on ten fingers. With base 2, numbers are enumerated as powers of 2: instead of units, tens, hundreds (102) and thousands $\left(10^{3}\right)$, the digits of a binary number refer to $1\left(2^{0}\right), 2\left(2^{1}\right), 4\left(2^{2}\right), 8\left(2^{3}\right)$ and so on. 
Leibniz pointed out in 1703 that to do simple arithmetic in binary, such as addition and multiplication, you don't need to memorize such rules as $5+4=9$, or $6 \times 7=42$. Instead, you need only apply a few simple rules. For addition, say, you just add the $1 \mathrm{~s}$ and 0 s, remembering that $1+1=1$ in the next position; for example, $100+101=1001$.


Leibniz GW(1703)

Gottfried Leibniz (1646-1716) is often credited for having invented the base-2 number system.

\section{Mixing systems}

The downside to binary is that large numbers require lots of digits. But according to psychologists Andrea Bender and Sieghard Beller of the University of Bergen in Norway, the authors of the latest study, the Mangarevan people found an ingenious answer to that, which they were apparently using even before 1450 ad.

Mangareva is a volcanic island whose first settlers arrived around $500-800$ ad. It probably had a population of several thousand before substantial interactions with Europeans began in the eighteenth century. Its highly stratified society survived mostly on seafood and root crops, and needed a number system to quantify large transactions in trade and in tributes made to chieftains.

Only about 600 Mangarevan speakers now remain on the island, and in any case its indigenous number system has long been superseded by Arabic digits because of the influence of French colonialism. But Bender and Beller have reconstructed it from descriptions written by (mostly European) authors in the nineteenth and early twentieth centuries ${ }^{2}$.

They find that the former Mangarevans combined base-10 representation with a binary system. They had number words for 1 to 10 , and then for 10 multiplied by several powers of 2. The word takau (which Bender and Beller denote as K) means 10; paua (P) means 20; tataua $(\mathrm{T})$ is 40 ; and varu $(\mathrm{V})$ stands for 80 . In this notation, for example, 70 is TPK and 57 is TK7.

Bender and Beller show that this system retains the key arithmetical simplifications of true binary, in that you don't need to memorize lots of number facts but follow only a few simple rules, such as $2 \times \mathrm{K}=\mathrm{P}$ and $2 \times \mathrm{P}=\mathrm{T}$.

Although this system has its drawbacks, "the advantages outweigh the disadvantages", the authors told Nature.

\section{Cultural factors}

Cognitive scientist Rafael Nuñez at the University of California, San Diego, points out that the idea of binary systems is actually older than Mangarevan culture. "It can be traced back to at least ancient China, around the 9th century bc", he says, and it can be found in the I Ching, a millennia-old Chinese text that inspired Leibniz. Nuñez adds that "other ancient groups, such as the Maya, used sophisticated combinations of binary and decimal systems to keep track of time and astronomical phenomena. Thus, the cognitive advantages underlying the Mangarevan counting system may not be unique."

All the same, say Bender and Beller, a 'mixed' system such as this is not easy, nor an obvious set-up to create. "It's puzzling that anybody would come up with such a solution, especially on a tiny island with a small population," Bender and Beller say. But they add: "This very fact also demonstrates just how important culture is for the development of numerical cognition — for example, how in this case dealing with big numbers can motivate inventive solutions."

Nuñez agrees; he adds that the study shows "the primacy of cultural factors underlying the invention of number systems, and the diversity in human numerical cognition".

Nature I doi:10.1038/nature.2013.14380

\section{References}

1. Bender, A. \& Beller, S. Proc. Natl Acad. Sci. USA http://dx.doi.org/10.1073/pnas.1309160110 (2013).

2. Bender, A. J. Polynesian Soc. 122, 275-287 (2013). 